\title{
Reversal in infant mortality in Kenya based on type of place of residence
}

\section{Omedi Gilbert}

\author{
Lecturer in Geography, Kaimosi Friends University College, \\ Kenya \\ Email: gilbertmaube@gmail.com
}

\begin{abstract}
Context: In the recent past, infant mortality has declined more rapidly in rural Kenya than urban Kenya. This paper sought to ascertain the factors responsible for the observed reversal in infant mortality in Kenya based on type of place of residence, defined as either urban or rural.

Data source and methods: The study used data obtained from 2014 Kenya demographic and health survey. Survival analysis was employed on child-recoded data set to estimate the risk of a neonate, post-neonate or an infant dying in urban or rural areas based on selected study variables.

Results: The study found early childhood mortalities to be significantly related to educational qualification of the mother, household wealth index, maternal age, size at birth, and place of delivery in both urban and rural Kenya. In urban Kenya, the study further found early childhood mortalities to be significantly related sex of the birth and the preceding birth interval.

Conclusion: The study suggests the need to check on lifestyle especially among the urbanites and to delay entry into childbearing as some of the measures to make infant mortality reduction mission a success.
\end{abstract}

Keywords: urban Kenya, rural Kenya, early childhood mortalities, survival analysis.

\section{Introduction}

High early childhood mortalities remain a threat to the socioeconomic advancement of any nation. It is with this recognition that the United Nations came up with the Millennium Development Goal number four that aimed at reducing infant and child mortality by two-thirds in a span of 25 years, that is, from 1990 to 2015. With it, respective national governments intensified efforts to reduce infant and child mortality, and enhance child survival, and this surely bore fruits as there are evident reductions in infant and child mortality rates worldwide. Nonetheless, the reductions do not necessarily point to the attainment of the goal as majority of the countries recorded a snail-pace reduction in the rates. At the elapse of the 25-year period, in the year 2015, the United Nations adopted Sustainable Development Goal number three which aim at ensuring healthy lives and promoting well-being for all at all ages. Target 3.2 of the goal reads "by 2030, end preventable deaths of newborns and children under five years of age, with all countries aiming to reduce neonatal mortality to at least as low as 12 per I,000 live births and under-five mortality to at least as low as 25 per 1,000 live births".

In Kenya, infant mortality rate is on a downward trend since the year 2003 when it was at 77 deaths per I,000 live births to the current 39 deaths per I,000 live births. Several factors have been suggested to explain the decline, among them: improvements in utilization of maternal health care services such as deliveries in health facilities, deliveries by skilled health providers, uptake of postnatal care services, improved healthcare seeking behavior for childhood illnesses such as pneumonia, diarrhea and malaria, and increased levels of ownership and use of insecticide-treated mosquito nets (KNBS and ICF Macro 2015). Considering type of place of residence, Kenya's infant mortality is documented to have been high in rural than urban areas till the year 2008 when we had a reversal: Urban-57, Rural-59 (1989), Urban-46, Rural-65 (1993), Urban-55, Rural-74 (I998), Urban-6I, Rural-79 (2003), Urban-63, Rural58 (2008), Urban-43, Rural-40 (20/4). With the rapidly increasing levels of urbanization in Kenya, and an increasing number of Kenyans preferring to reside in urban than rural areas, then there shall be an increased proportion of births in urban than rural Kenya, and this pattern might also be reflected in early childhood mortalities. This paper therefore sought to ascertain the factors responsible for the observed reversal in rural-urban infant mortality in Kenya and bring out possible reasons for the diminishing urban advantage in terms of infant mortality. An understanding of the factors behind the high urban than rural infant mortality will enable policy makers, programmers and implementers to attempt to address the situation whose overall repercussion will be a reduced nation-wide infant 
mortality that shall keep us on track towards the attainment of the third Sustainable Development Goal.

While appreciating the kind of effort that Kenya put in place to see a reduction in childhood mortalities in since the inception of the Millennium Development Goals by the United Nations, it is imperative to recall that she did not attain the Millennium Development Goal number four as she was expected to record an infant mortality rate of 20 deaths in every I,000 live births by the year 2015. Contrarily, KNBS and ICF Macro 2015 reported an infant mortality rate of 39 deaths in every I,000 live births implying that about one in every twenty-six children in Kenya dies before reaching age one. The wide variation between neonatal mortality rate (22) and post neonatal mortality rate (16) confirms it that causes of death varies with age and therefore a study on infant mortality should be age-segmented. Neonatal mortality is the probability, per I,000, of a live birth dying between birth and 28 days of life if subjected to the current age-specific mortality rate. Post neonatal mortality, on the other hand, is the probability, per 1,000 , of a life birth dying between 29 days to less than one year if subjected to the current age-specific mortality rate.

\section{Literature review}

Over time, and in many developing nations, infant mortality rates have generally been reported to be higher in rural than urban areas. The possible reasons have been unavailable and/or inaccessible health services, long travel distances to health centers, minimal educational qualifications of the parents, hard economic times, young maternal ages, among others, among rural dwellers than urban dwellers. In the recent past, few regions have shown a reversal in that infant mortality rate is high in urban than rural areas (KNBS and ICF Macro 20I5, 20I0). This is a reflection of either the deteriorating living conditions in urban settings as compared to the rural areas, or the rapid improvement in socioeconomic conditions in rural areas as compared to urban areas. Yet still, the effects of economic crisis are felt much more in urban than rural settings, and childhood mortality being much sensitive to fluctuations in the standards of living may explain high urban than rural infant mortality rates. Further, as nations approach the final stages of the demographic transition, there emerges congenital anomalies, injuries and non-communicable diseases such as chronic respiratory diseases, acquired heart diseases, childhood cancers, diabetes and obesity, all of which are more likely to occur in urban than rural areas and have a known influence on mortality when they go unaddressed.
Maternal education has been found to account for differentials in childhood mortality (Faye et al., 2016; Pena et al., 2000; Caldwell and McDonald 1982). Education improves the status of women, increases age at marriage, reduces unwanted fertility and improves the utilisation of health services by contributing towards self-confidence of women, improving their maternal skills, increasing their exposure to information and thereby altering the way others respond to them. Higher education attainment is linked with lower fertility, reproduction at low-risk ages and longer birth intervals all of which improves the health condition of both the mother and the child. Mondal et al. (2009) found the risk of neonatal mortality to be 31.4 percent and 52.3 percent lower among women having primary and at least secondary education respectively than those having no education. Even with better coverage of maternal and child health care services, education greatly influences the disparity in service utilisation and hence the probability of child survival (Taffa and Obare, 2004). Other studies have however found an unclear effect of maternal education on childhood mortality. Using Cox proportional hazard model to analyse the direct, indirect and total percentage change of childhood mortality with respect to maternal education, Abou-Ali (undated) found a low educated mother to contribute more to the reduction in neonatal mortality than a medium and high educated mother. He attributed this to the fact that more educated mothers are employed and thus do not have sufficient time to take care of their children. When forced to work, the mother is often obliged to leave the child with insufficient care that may expose the child to danger.

A mother's work status has a two-way influence on child survival. A mother who works outside home is prevented from adequately caring for the infant. The dual burden of employment and household work can reduce the time available for child care services. This results to substantial effect through lack of proper feeding especially breastfeeding in the early stages of life. On the other hand, mothers working outside home can have increased income that results in higher family income and gives the mother a modern outlook, both of which can increase the probability of child survival. Mondal et al. (2009) found the risk of neonatal death to be 37.9 percent lower among working mothers than those who were not working. They attributed the lower risk of infant mortality among working mothers to be due to the fact that they might be well aware about immunisation and care during pregnancy. Counterintuitively, a mother who works at home is likely to have reduced income making her unable to provide better health services to the infant because of high 
consultancy fee for the qualified medical personnel, and costly medical tests and medicines. This makes them to prefer home remedies and cheap and near facilities that might not improve infant health standards.

Wealth status is used as a determinant of the availability of nutritional resources especially when infants reach the age of six months when they can no longer depend on nourishment from breast milk alone (Kembo and van Ginneken 2009). It is also used to measure discrepancies in the utilisation of health services, especially where perceived expenses may hinder access and utilisation of such services (Babalola and Fatusi 2009). Such expenses include transport costs to health facilities and the purchase of medications. Nonetheless, it is unclear whether offering free health services such as antenatal care and maternal and child health services would lead to a change in the utilization of health services since transport costs, the physical inability to travel long distances and poor quality of care would remain important barriers (Gabrysch and Campbell, 2009). According to Case et al. (2002), children from lower income households with chronic conditions have worst health than do those from higher income households. Fotso et al. (2007) reported that the poor have almost three times more children than the rich, they are also three times less likely to use contraception and three times more likely to have unmet need for family planning. Such poor reproductive health outcomes could further worsen child health outcomes among the poor. Their findings suggest that the high fertility of the poor may be largely unplanned or unwanted. With growing poverty and growing poor-rich fertility gap, greater proportions of children are increasingly born to poor families (Brockerhoff and Brennan, 1998) yet the relationship between fertility and mortality is well known. Adedini (20/4) found births to women in richer and richest wealth indices to have a significantly lower risk death than those births to women in the poorest and poorer wealth indices.

Young age at motherhood is biologically not fully mature and there are high chances of pregnancy related complications that might lead to the death of the newborn baby. Such a mother is also unlikely to provide good care for the infant appropriately and may lack the domestic decision-making authority that older mothers may have. Other risks of early pregnancy and motherhood include: increased risks of dying, increased risk of premature labour, complications during delivery, low birth weight, and higher chances that the newborn will not survive. While studying factors influencing infant and child mortality in Rajshahi District of Bangladesh, Mondal et al. (2009) found the risk of neonatal and post- neonatal mortality to be 42.1 percent and 72.4 percent respectively, lower among mothers in the age group 30-49 than those whose age is less than 20 years. Taffa and Obare (2004) concluded that children of young mothers might be prone to have severe forms of infections and likely to die of it, and that this is a double disadvantage for teenagers living in poor rural areas. Further explanations for adverse birth outcomes among teenagers are that a pregnant teenager who is still growing may be competing for nutrients with the foetus, pregnancy within two years after menarche increases the risk of preterm delivery, unwanted and unplanned pregnancies (Reichman and Pagnini, 1997). Older women, on the other hand, suffer increased risks of poor birth outcomes due to biological risks of increased likelihood of such medical conditions as diabetes and hypertension, and higher rates of unintended pregnancies compared to women in their twenties and early thirties (La Grew et al., 1996; Brown and Eisenberg, 1995).

Low birth weight due to prematurity or intrauterine growth retardation remains a risk factor for poor neurosensory, cognitive, and behavioural development, and for limited school performance and academic achievement (Taylor et al., 2000; Teplin et al., 1991). The most vulnerable group of low birth weight are prematurely-born infants who were found to be four times more likely to experience failure in school than infants of normal birth weight and they need special support or educational services (Hack et al., 1995). An analysis of cross-sectional data on birth weight and survival from five sites in sub-Saharan Africa showed that infant mortality is three times higher for low birth weight babies than for those of normal weight (Guyatt and Snow, 200I). The effects on neonatal mortality are even more marked, with a low birth weight baby being nine times more likely to die in the first month of life than a normal weight baby.

Antenatal care aims at identifying and treating problems such as anaemia and infections, and screening for complications and advice on a range of issues such as place of delivery and referral of mothers. A lot of time women go for antenatal services for the sake of obtaining cards which they will need when taking their babies for postnatal care services. This probably explains the high antenatal care uptake and low skilled assistance during delivery observed in Kenya. KNBS and ICF Macro (2010) document that though 91.5 percent of births occurred to women who had ever received antenatal care from a skilled provider, only 42.6 percent of these births occurred in a health facility while 43.8 percent were delivered by the assistance of skilled personnel. That not all women who initiate antenatal 
visits go up to at least the recommended number of four visits is not surprising. Access to antenatal care is used as a predictor of full immunisation uptake besides pointing to the quality of care received by mothers and infants during delivery. Women who attend antenatal care services are more likely to be informed of the importance of childhood immunisation and other important health-promoting programs. Lack of antenatal care especially in rural areas with deficiency in health facilities and skilled healthcare workers is one of the explainers of the existing rural-urban inequities in childhood immunisation, yet the relationship between childhood immunisation coverage and childhood mortality is well known.

There exists a linkage between place of delivery and mortality, evidence showing that women who deliver in health facilities have lower probabilities of reporting infant deaths as compared to those who deliver in home settings (Worku, 2009; Doctor, 20II). These differences are largely a result of use of skilled delivery care and sanitary environments at health facilities unlike deliveries that occur at home which are largely not attended to by skilled birth attendants often times in unsanitary environments (Ettarh and Kimani, 2012; Pandey et al., 1998). Using Cox's regression model, Taffa and Obare (2004) found home delivery to be 1.3 and 0.8 times more likely to be related to infant mortality among women aged 20-34 than those that delivered in a health facility in Kenya and Uganda respectively. Nonetheless, in some cases, children delivered in modern health facilities exhibit higher mortality because mothers tend to use these facilities mostly when they experience pregnancy complications (Ajaari et al., 2012; Kembo and van Ginneken, 2009). Even so, not every health facility is fully equipped with the necessary equipment and practitioners to offer such delivery services, example, those in rural and informal settlements. In their study on "What explains the rural-urban gap in infant mortality: household or community characteristics?" Van de Poel et al. (2009) noted the existence of a health facility to be correlated to a reduced risk of infant death with the effect being strongly significant only in urban areas. The lack of significance in rural areas may be a reflection of the low quality of health services with frequent absences of staffs and medicines, or the lower probability of seeking health care in rural areas because of the high opportunity costs and cultural sensitivity (Say and Raine, 2007; Lalou and LeGrand, 1997).

\section{Operational framework}

Figure $\mathrm{I}$ is an illustration of the operational framework employed in this study. The framework is a modification of the conceptual model by Mosley and Chen (1984) that recognizes that socio-economic factors operate through a set of intermediate variables (proximate determinants) to influence the risk of disease, and in its turn, childhood mortality observed in any given population. The independent variables are the level of education of the mother, household wealth index, work status of the mother, maternal age, size at birth, preceding birth interval, number of antenatal care visits, and place of delivery. Maternal age is found by observing the following steps: compute year of birth of the mother by subtracting current age of the mother from the year of interview, then compute maternal age by subtracting year of birth of the mother from the year of birth of the child. The dependent variable, infant mortality, measures time to death: whether between birth and 28 days of life, or between 29 days of life to less than one year. Infant mortality is used as the dependent variable since death is unusual and a rare event and it is easily calculated (Mosley and Chen 1984). 
Fig I: An illustration of the operational framework

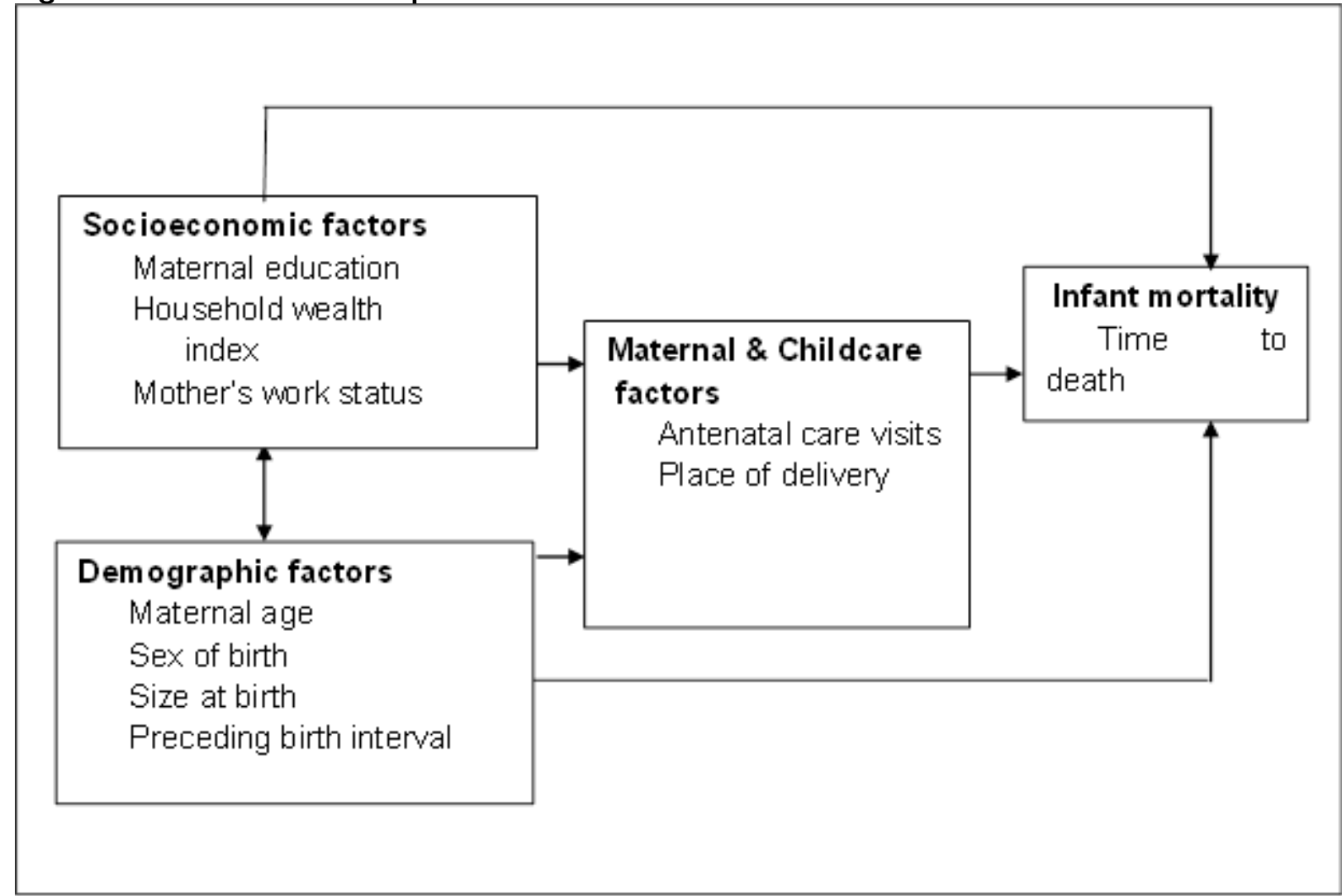

Modified from Mosley and Chen (1984) Conceptual Model

\section{Data and methods}

The study used highly reliable cross-sectional children recode data collected during the 2014 Kenya Demographic and Health Survey (KDHS). The 2014 $\mathrm{KDHS}$ was a nationally representative probability sample survey of 39,679 households of which 36,812 were found occupied at the time of the fieldwork. A total of 31,079 out of 32,172 eligible women were successfully interviewed, giving a response rate of 96.6 percent. During the survey, each female respondent of the reproductive age was asked using a woman's questionnaire to report on her background characteristics of education, residential history and media exposure, the number of sons and daughters who lived with her, the number who lived elsewhere and the number who had died. The respondent was also to provide a detailed birth history of her child bearing experience, entailing the sex of the birth, whether the birth was singleton or multiple, survival status, current age of each of the live birth, and if not alive, the age at death of each of the live birth. Further, the questionnaire captured information on antenatal, delivery and postnatal care, breastfeeding, immunisation, nutrition and childhood illnesses, fertility preferences, among other information. After identifying eligible individuals for the interview, the household questionnaire further collected information on the characteristics of the household's dwelling unit: source of water, type of toilet facility, http://aps.journals.ac.za materials used for the floor, wall and roof of the house, ownership of various durable goods, agricultural land and domestic animals, ownership and use of mosquito nets, etc. The survey therefore provided data for a wide range of monitoring and impact evaluation in the areas of population, health and nutrition.

Analysis was done at two levels: descriptive and inferential levels. At descriptive level, cross-tabulation analysis was done to measure the prevalence of infant deaths in the selected covariates. Chi-square statistic was used to determine the magnitude of the prevalence between the dependent variable and the selected independent variables. Cox regression analysis was done at inferential level to bring out the risk of an infant dying before celebrating its first birthday based on the study variables that were be found significant in logistic regression analysis. Besides accounting for censoring in the estimation of exposure time, Cox analysis offers several regression models for estimating the relationship of continuous variables to survival times.

The regression model is given by: $h(t)=h 0(t) * \exp (\beta|x|+\ldots \ldots .+\beta n x n) \quad$ where: $h(t)$ is the hazard rate; $h 0(t)$ is the baseline hazard; and $\beta \mid \ldots . . \beta n$ are the associated coefficients for the respective cases $(x \mid \ldots . . x n)$ 
When we divide both sides of the above equation by $\mathrm{hO}(\mathrm{t})$ and take natural logarithms of both sides, we obtain:

$\ln \{\mathrm{h}(\mathrm{t}) / \mathrm{h} 0(\mathrm{t})\}=\beta|\mathrm{x}|+\ldots \ldots . .+\beta$ nxn where: $\mathrm{h}(\mathrm{t}) / \mathrm{hO}(\mathrm{t})$ is the hazard ratio.

As mentioned by Omedi and Wanjiru (20I4), the regression coefficient indicates the relative effect of the covariate on the hazard function. A positive coefficient, in this study, indicated a greater probability of the risk of infant death and a negative coefficient indicated a lesser risk of infant death. The hazard function made it easy to calculate the relative risk of certain groups in relation to the reference categories by the exponentiation of the coefficient so as to obtain the odds ratio. Since the relative risk for the reference category is one, odds ratios greater than one indicate a greater relative risk of dying for the specified group with respect to the reference group whereas odds ratios less than one indicate a lesser risk.

Three models were estimated in order to ascertain the risk of the selected variables on infant death: Model I contained socioeconomic factors as the only exposure variables; Model II contained socioeconomic and demographic factors as exposure variables, while Model III contained all the factors (socioeconomic, demographic, and maternal and childcare factors as exposure variables in order to assess the net effect of each variable after controlling for all other variables. Considering survival analysis involves censored events, the IMR fitted in the time slot in the Cox model was found by observing the following steps: compute IMR = b7, then recode it into the same variable whereby system or user missing $=99$. The recoded infant status was fitted in the status slot and the event defined as 'dead'. The respective independent variables were fitted in the covariates slot and categorised whereby the reference category was indicated as the first.

\section{Results}

\section{Prevalence of infant deaths}

Cross-tabulation analysis was carried out to measure the prevalence of infant deaths as neonates, post- neonates and infants based on the selected covariates. The results are as shown in Table I. Such percentage distributions are important in giving a general idea on how skewed the variables of study are considering that in social sciences most of the distributions are rarely absolutely normal. Of the 729 infant deaths, $252(34.57 \%)$ occurred in urban areas whereas $477(65.43 \%)$ occurred in rural areas. Generally, majority of infant deaths were of babies aged less than, or exactly, one month old (neonates) than it were for babies aged above one month but less than twelve months of life (post-neonates).

Considering the socioeconomic background factors, majority of deaths were among mothers with primary educational qualifications and those that were currently working as at the time of the survey. It is however surprising that, in urban Kenya, more infant deaths (36.5I\%) occurred to women with some secondary education than they occurred to women with no education at all (13.10\%). Unlike in urban Kenya where majority of infant deaths (57.94\%) were reported in high wealth index households, only 12.37 percent of infant deaths occurred in high wealth index households in rural Kenya with 68.55 percent of infant deaths being reported in low wealth index households.

Geographically, more male than female babies died at infancy with an extremely modest differential in urban areas $(50.40 \%$ versus $49.60 \%)$. In urban areas, male deaths reduced from neonate to postneonate age while they increased in rural areas. There were more deaths among infants who were of a preceding birth interval of at least two years and of average size at birth, an indicator of birth weight, and of those born to mothers aged 20 to 29 years. However, it should be noted that, based on the 2014 Kenya demographic and health survey data, motherhood in Kenya begin as early as age 12: 1, 5 and $5 \mathrm{I}$ infants died to mothers aged 12,13 and 14 years respectively. This can be attributed to modernization and changes in lifestyle and diets that brings about new culture (whereby coitus is no longer a preserve for the married), and biological and hormonal adjustments in girls.

Table I: Percentage of neonate, post-neonate and infant deaths based on the study variables, 20I4 KDHS

\begin{tabular}{|c|c|c|c|c|c|c|}
\hline \multirow[b]{2}{*}{ Variable name } & \multicolumn{3}{|c|}{ URBAN } & \multicolumn{2}{|c|}{ RURAL } & \multirow[b]{2}{*}{ Infants } \\
\hline & Neonates & Post-neonates & Infants & Neonates & Post-neonates & \\
\hline \multicolumn{7}{|c|}{ Highest educational qualification of the mother } \\
\hline No education & 14.38 & 10.87 & 13.10 & 26.89 & 20.55 & 24.95 \\
\hline Primary education & 51.25 & 48.91 & 50.40 & 58.01 & 62.33 & 59.33 \\
\hline Secondary+ education & 34.38 & 40.22 & 36.51 & $15.1 \mid$ & 17.12 & 15.72 \\
\hline Pearson Chi-square value & 1.158 & & & 2.214 & & \\
\hline
\end{tabular}


Household wealth index

\begin{tabular}{lcc} 
Low & 26.25 & 22.83 \\
Medium & 17.50 & 16.30 \\
High & 56.25 & 60.87 \\
Pearson Chi-square value & 0.538 & \\
\hline
\end{tabular}

\begin{tabular}{llll}
25.00 & 66.16 & 73.97 & 68.55 \\
17.06 & 21.15 & 14.38 & 19.08 \\
57.94 & 12.69 & 11.64 & 12.37 \\
& 3.421 & & \\
\hline
\end{tabular}

Current work status of the mother

\begin{tabular}{lcccccc} 
Not currently working & 40.58 & 23.40 & 33.62 & 35.50 & 36.67 & 35.81 \\
Currently working & 59.42 & 76.60 & 66.38 & 64.50 & 63.33 & 64.19 \\
Pearson Chi-square value & 3.695 & \multicolumn{5}{c}{0.026} \\
\hline
\end{tabular}

Sex of the birth

\begin{tabular}{lcccccc} 
Male & 50.63 & 50.00 & 50.40 & 58.01 & 61.64 & 59.12 \\
Female & 49.38 & 50.00 & 49.60 & 41.99 & 38.36 & 40.88 \\
Pearson Chi-square value & 0.009 & & & 0.555 & \\
\hline
\end{tabular}

Preceding birth interval

Less than 24 months

$30.19 \quad 25.37$

28.32

$30.83 \quad 28.00$

29.92

At least 24 months

$69.81 \quad 74.63$

71.68

69.17

72.00

70.08

Pearson Chi-square value

0.469

0.324

\section{Maternal age}

Under 20

20 to 29

11.88

17.39

13.89

16.31

14.38

15.72

30 to 39

57.50

58.70

57.94

46.53

56.85

49.69

40 to 49

27.50

19.57

24.60

30.21

25.34

28.72

$3.13 \quad 4.35$

3.57

6.95

3.42

5.87

Pearson Chi-square value

Size at birth

\begin{tabular}{lclllll} 
Small & 39.44 & 8.89 & 27.59 & 31.37 & 16.67 & 27.23 \\
Average & 35.21 & 66.67 & 47.41 & 42.48 & 61.67 & 47.89 \\
Large & 25.35 & 24.44 & 25.00 & 26.14 & 21.67 & 24.88 \\
Pearson Chi-square value & 15.074 & & & 7.082 & \\
\hline
\end{tabular}

Number of antenatal care visits

$\begin{array}{lcccccc}\text { None } & 8.43 & 6.38 & 7.69 & 17.61 & 13.56 & 16.51 \\ \text { I to 3 visits } & 36.14 & 31.91 & 34.62 & 38.36 & 38.98 & 38.53 \\ \text { At least 4 visits } & 55.42 & 61.70 & 57.69 & 44.03 & 47.46 & 44.95 \\ \begin{array}{l}\text { Pearson Chi-square value } \\ \text { Place of delivery }\end{array} & 0.524 & & & 0.545 & & \\ \text { Home } & 30.38 & 20.45 & 26.83 & 53.85 & 59.86 & 55.73 \\ \text { Public sector } & 56.96 & 60.23 & 58.13 & 38.14 & 35.92 & 37.44 \\ \text { Private sector } & 12.66 & 19.32 & 15.04 & 8.01 & 4.23 & 6.83 \\ \text { Pearson Chi-square value } & 3.846 & & & 2.812 & & \end{array}$

Infant death cases increased from mothers who did not attend any antenatal care visit to those who attended a minimum of four visits both in urban and rural Kenya. Can it be assumed that the babies born to mothers who did not attend any antenatal care visit were higher order births in that their mothers had some experience in child bearing and rearing? As expected, there were many infants dying among mothers who did home deliveries (55.73\%) than them that did hospital deliveries (44.27\%) in rural areas of Kenya. The trend was different in urban areas where 58.13 percent, 26.83 percent and 15.04 percent of infant deaths were to mothers who did deliveries in public hospitals, at home and in private hospitals respectively. 
Results of inferential analysis

Tables 2 and 3 present the inferential analytical findings of the determinants of neonatal, post neonatal and infant mortalities in urban and rural Kenya respectively.

Table 2: Odds ratios of neonate, post-neonate and infant deaths in urban Kenya

\begin{tabular}{|c|c|c|c|c|c|c|c|c|c|}
\hline \multirow[b]{2}{*}{ Variable name } & \multicolumn{3}{|c|}{ Neonate death } & \multicolumn{3}{|c|}{ Post-neonate death } & \multicolumn{2}{|c|}{ Infant death } & \multirow[b]{2}{*}{$\begin{array}{l}\text { Model } \\
\text { III }\end{array}$} \\
\hline & \multicolumn{2}{|c|}{ Model } & $\begin{array}{l}\text { Model } \\
\text { III }\end{array}$ & Model & $\begin{array}{l}\text { Model } \\
\text { II }\end{array}$ & $\begin{array}{l}\text { Model } \\
\text { III }\end{array}$ & Model I & $\begin{array}{l}\text { Model } \\
\text { II }\end{array}$ & \\
\hline \multicolumn{10}{|c|}{$\begin{array}{l}\text { Highest educational qualification of the } \\
\text { mother }\end{array}$} \\
\hline No education & 1.000 & 1.000 & 1.000 & 1.000 & 1.000 & 1.000 & 1.000 & 1.000 & 1.000 \\
\hline $\begin{array}{l}\text { Primary education } \\
\text { Secondary }+\end{array}$ & 1.542 & 1.479 & 0.770 & 0.836 & 0.347 & 7.389 & 1.247 & 1.324 & 0.844 \\
\hline education & 1.847 & 1.799 & 1.003 & 0.791 & $0.228^{*}$ & II.387 & $1.35 \mathrm{I}$ & 1.398 & 1.006 \\
\hline \multicolumn{10}{|c|}{ Household wealth index } \\
\hline Low & 1.000 & 1.000 & 1.000 & 1.000 & 1.000 & 1.000 & 1.000 & 1.000 & 1.000 \\
\hline Medium & 0.687 & 1.058 & 0.827 & 0.997 & 1.934 & $\begin{array}{l}3.394 \\
10.95 I^{*}\end{array}$ & 0.737 & 1.186 & 0.863 \\
\hline High & $0.57 I^{*}$ & 0.577 & 0.580 & 1.373 & $2.169 *$ & * & 0.776 & 0.896 & 1.010 \\
\hline \multicolumn{10}{|c|}{ Current work status of the mother } \\
\hline $\begin{array}{l}\text { Not currently } \\
\text { working }\end{array}$ & 1.000 & 1.000 & 1.000 & 1.000 & 1.000 & 1.000 & 1.000 & 1.000 & 1.000 \\
\hline Currently working & 0.754 & 0.789 & 1.076 & 1.378 & 0.434 & 0.231 & 0.928 & 0.842 & 0.968 \\
\hline \multicolumn{10}{|l|}{ Sex of the birth } \\
\hline Male & & 1.000 & 1.000 & & 1.000 & 1.000 & & 1.000 & 1.000 \\
\hline Female & & 1.263 & 1.587 & & 0.721 & $0.308^{*}$ & & 0.880 & 0.961 \\
\hline \multicolumn{10}{|c|}{ Preceding birth interval } \\
\hline Less than 24 months & & 1.000 & 1.000 & & 1.000 & 1.000 & & 1.000 & 1.000 \\
\hline At least 24 months & & 0.700 & 1.420 & & 0.775 & $0.274 *$ & & 0.771 & 0.952 \\
\hline \multicolumn{10}{|l|}{ Maternal age } \\
\hline Under 20 & & 1.000 & 1.000 & & 1.000 & 1.000 & & 1.000 & 1.000 \\
\hline 20 to 29 & & 1.684 & 1.158 & & 1.942 & $9.067^{*}$ & & $\begin{array}{l}1.592 \\
2.355^{*}\end{array}$ & 0.895 \\
\hline 30 to 39 & & 2.409 & 1.528 & & $4.564^{*}$ & |4.204 & & 4.482* & 1.210 \\
\hline 40 to 49 & & 3.929* & 3.449 & & 1.000 & 1.000 & & * & 2.368 \\
\hline \multicolumn{10}{|l|}{ Size at birth } \\
\hline Small & & 1.000 & 1.000 & & $\begin{array}{l}1.000 \\
8.413^{*}\end{array}$ & 1.000 & & 1.000 & 1.000 \\
\hline Average & & $0.528 *$ & $0.346 *$ & & **⿻丷木 & 1.596 & & 0.987 & 0.607 \\
\hline Large & & 0.828 & 0.567 & & $5.055^{*}$ & I.785 & & 0.853 & 0.591 \\
\hline \multicolumn{10}{|c|}{ Number of antenatal care visits } \\
\hline None & & & 1.000 & & & 1.000 & & & 1.000 \\
\hline I to 3 visits & & & 0.632 & & & 0.972 & & & 0.662 \\
\hline At least 4 visits & & & 0.529 & & & & & & 0.615 \\
\hline \multicolumn{10}{|l|}{ Place of delivery } \\
\hline Home & & & 1.000 & & & 1.000 & & & 1.000 \\
\hline Public sector & & & 1.026 & & & $0.05 I^{* * *}$ & & & 0.745 \\
\hline Private sector & & & 0.858 & & & $0.036 * *$ & & & 0.592 \\
\hline - 2 log likelihood & 672.45 & & 193.24 & 360.5 & 227.6 & & 1038.9 & 652.98 & 315.50 \\
\hline ratio & 3 & 405.242 & 2 & 99 & $\begin{array}{l}25 \\
13.72\end{array}$ & 108.742 & 05 & & \\
\hline Chi-square test & 5.978 & 12.701 & 12.281 & 1.916 & 8 & 10.993 & 2.032 & 8.047 & 9.770 \\
\hline
\end{tabular}


In every category of early childhood mortality, three models are presented: Model I shows the risk of socioeconomic factors on mortality, Model II shows the risk of socioeconomic and demographic factors on mortality, whereas Model III shows the risk of socioeconomic, demographic and maternal and childcare factors on mortality so as to assess the net effect of each variable after controlling for all other variables. Testing the risk other than the likelihood of death was perceived to be a good measure in bringing out an understanding of the factors likely to be responsible for the observed change in infant mortality rates based on type of place of residence.

Results in Table 2 show that the socioeconomic factors responsible for early childhood mortalities in urban areas of Kenya are highest educational qualifications of the mother and the household wealth index. Babies born to mothers with some secondary education were found to be at a 0.772 lesser risk of dying at post-neonatal stages than those born to mothers with no any educational qualifications.

Neonates born in high wealth index households had a 0.429 lower probability of dying than those born in low wealth index households in Model I. The study found the risk of death at post-neonate stage to be 1.169 and 9.951 higher in high wealth index households than in low wealth index households in Models II and III respectively. Current work status of the mother was not found to be statistically associated to the risk of death in either age segment.

Demographically, all the study covariates were found to be at least associated with early childhood mortalities at 99 percent, 95 percent and 90 percent significance levels. Female births had a 0.692 lower risk of dying at post-neonatal stage than their male counterparts when all the study variables were incorporated in the model. Yet still, babies born at a preceding birth interval of at least 24 months were at a 0.726 lower risk of dying as post-neonates than those born at a preceding birth interval of less than 24 months. For infants, in Model II, the risk of death increased with increase in maternal age. At 95 percent statistical significance level, infants born to mothers aged 30 to 39 and 40 to 49 years had a 1.355 and 3.482 higher risk of dying, respectively, than their counterparts born to mothers aged less than 20 years. Unlike neonates who were reported as of average size at birth who had a lower risk of death than those of small birth size, average-sized-atbirth post-neonates had a higher risk of death than small-sized-at-birth post-neonates. On maternal and childcare factors, which were introduced in the full model, the risk of post-neonate death steadily reduced from home deliveries to deliveries in the public health facilities to deliveries in private health facilities.

In Table 3, it was found that the socioeconomic factors responsible for early childhood mortalities in urban areas are the same factors responsible for such mortalities in rural areas. In rural Kenya, neonates born to mothers with primary educational qualifications were at a 0.394 and 0.34 I lower risk of dying in Model I and Model II respectively, than those born to mothers with no any educational qualifications. During infancy, births to mothers with primary educational qualifications were found to be at a 0.228 lower probability of dying than those born to mothers with no any educational qualifications in Model I. The disappearance of the statistical significance in the full models implies that the introduction of maternal and childcare factors tends to lower the effect of maternal educational qualifications on mortality. Save for neonates who had a lower risk of dying in high wealth index households than their colleagues in low wealth index households (in Model III), post-neonates and infants in high wealth index households were at a higher risk of dying than their colleagues in low wealth index households.

Demographically, in Models II, the risks of death were 0.797 and 0.408 lower among post-neonates and infants born to mothers aged 20 to 29 years than their colleagues born to mothers aged less than 20 years. Still in Models II, average -sized births had $0.32 \mathrm{I}$ and 0.265 lower risks of dying as neonates and infants, respectively, than small-sized births in rural Kenya. In Model III, large-sized infants had a 0.347 lower risk of dying than small-sized infants. Unlike in urban Kenya, babies delivered in public health facilities in rural Kenya had 0.616 and 0.473 higher risks of dying as neonates and infants, respectively, compared to their colleagues delivered at home.

Table 3: Odds ratios of neonate, post-neonate and infant deaths in rural Kenya

\begin{tabular}{|c|c|c|c|c|c|c|c|c|c|}
\hline \multirow[b]{2}{*}{ Variable name } & \multicolumn{3}{|c|}{ Neonate death } & \multicolumn{3}{|c|}{ Post-neonate death } & \multicolumn{2}{|c|}{ Infant death } & \multirow[b]{2}{*}{$\begin{array}{l}\text { Mode } \\
\text { III }\end{array}$} \\
\hline & Model I & $\begin{array}{l}\text { Model } \\
\text { II }\end{array}$ & $\begin{array}{l}\text { Model } \\
\text { III }\end{array}$ & $\begin{array}{l}\text { Model } \\
\text { l }\end{array}$ & $\begin{array}{l}\text { Model } \\
\text { II }\end{array}$ & $\begin{array}{l}\text { Model } \\
\text { III }\end{array}$ & Model & $\begin{array}{l}\text { Model } \\
\text { II }\end{array}$ & \\
\hline \multicolumn{10}{|c|}{ Highest educational qualification of the mother } \\
\hline No education & $\begin{array}{l}1.000 \\
0.606 * *\end{array}$ & 1.000 & 1.000 & 1.000 & 1.000 & 1.000 & 1.000 & 1.000 & 1.000 \\
\hline Primary education & * & $0.659 *$ & 0.845 & 1.681 & 1.583 & 0.971 & $0.772 *$ & 0.819 & 0.826 \\
\hline
\end{tabular}




\begin{tabular}{|c|c|c|c|c|c|c|c|c|c|}
\hline $\begin{array}{l}\text { Secondary+ } \\
\text { education }\end{array}$ & 0.726 & 0.674 & 0.844 & 1.572 & 0.902 & 0.524 & 0.884 & 0.827 & 0.778 \\
\hline \multicolumn{10}{|c|}{ Household wealth index } \\
\hline Low & 1.000 & 1.000 & 1.000 & 1.000 & 1.000 & 1.000 & 1.000 & 1.000 & 1.000 \\
\hline Medium & $1.498 *$ & I.486* & 1.062 & 0.886 & 1.135 & 0.900 & 1.308 & 1.375 & 1.128 \\
\hline High & $1.37 \mid$ & 1.469 & $0.585^{*}$ & $\mathrm{I} .774$ & $3.106 * *$ & 2.120 & $1.407^{*}$ & $1.663^{*}$ & 0.951 \\
\hline \multicolumn{10}{|c|}{ Current work status of the mother } \\
\hline $\begin{array}{ll}\text { Not } & \text { currently } \\
\text { working } & \end{array}$ & 1.000 & 1.000 & 1.000 & 1.000 & 1.000 & 1.000 & 1.000 & 1.000 & 1.000 \\
\hline Currently working & 1.049 & 1.047 & 0.962 & 0.931 & 0.851 & 0.864 & 0.999 & 0.946 & 0.934 \\
\hline \multicolumn{10}{|l|}{ Sex of the birth } \\
\hline Male & & 1.000 & 1.000 & & 1.000 & 1.000 & & 1.000 & 1.000 \\
\hline Female & & 0.868 & 1.089 & & 0.938 & 0.909 & & 0.870 & 0.979 \\
\hline \multicolumn{10}{|c|}{ Preceding birth interval } \\
\hline Less than 24 months & & 1.000 & 1.000 & & 1.000 & 1.000 & & 1.000 & 1.000 \\
\hline At least 24 months & & 0.879 & 0.867 & & 1.069 & 0.913 & & 0.975 & 0.859 \\
\hline \multicolumn{10}{|l|}{ Maternal age } \\
\hline Under 20 & & 1.000 & 1.000 & & $\begin{array}{l}1.000 \\
0.203 * *\end{array}$ & 1.000 & & 1.000 & 1.000 \\
\hline 20 to 29 & & 0.779 & 1.180 & & $*$ & 0.897 & & $0.592 *$ & 0.944 \\
\hline 30 to 39 & & 0.842 & 1.331 & & $0.260 * *$ & 1.184 & & 0.667 & 1.127 \\
\hline 40 to 49 & & 1.126 & 2.654 & & 0.000 & 0.000 & & 0.734 & 1.820 \\
\hline \multicolumn{10}{|l|}{ Size at birth } \\
\hline Small & & 1.000 & 1.000 & & 1.000 & 1.000 & & 1.000 & 1.000 \\
\hline Average & & $0.679 *$ & $0.630 *$ & & 1.104 & 1.359 & & $0.735^{*}$ & 0.755 \\
\hline Large & & 0.928 & 0.704 & & 0.819 & 0.598 & & 0.885 & $0.653^{*}$ \\
\hline \multicolumn{10}{|c|}{ Number of antenatal care visits } \\
\hline None & & & 1.000 & & & 1.000 & & & 1.000 \\
\hline I to 3 visits & & & 0.735 & & & 0.947 & & & 0.765 \\
\hline At least 4 visits & & & 0.736 & & & 0.957 & & & 0.760 \\
\hline \multicolumn{10}{|l|}{ Place of delivery } \\
\hline Home & & & 1.000 & & & 1.000 & & & 1.000 \\
\hline Public sector & & & $1.616 *$ & & & $1.09 \mid$ & & & $1.473 *$ \\
\hline Private sector & & & 1.530 & & & 1.014 & & & 1.356 \\
\hline - 2 log likelihood & 1851.1 & 1299.5 & & $5 / 4.8$ & $4 / 5$ & & 2373.3 & 1730.3 & $1 / 36.7$ \\
\hline ratio & 3 & 5 & 820.59 & 2 & ${ }^{45} 16.4$ & 301.54 & 8 & 6 & 2 \\
\hline Chi-square test & 8.346 & 13.360 & 15.345 & 5.293 & 96 & 10.211 & 6.080 & 13.231 & 11.508 \\
\hline
\end{tabular}

* $\rho<0.1$; *** $\rho<0.05$; **** $\rho<0.01$

\section{Discussion}

Results of the reversal in infant mortality based on residence type in Kenya showed some similarities in the risk factors of early childhood mortalities in urban and rural Kenya. Highest educational qualifications of the mother, wealth index of the household in which the death occurred, maternal age, size of the baby at birth, and the place of delivery were the mortality risk factors in both urban and rural areas of Kenya.

Unlike in rural Kenya, the study found sex of the birth and preceding birth interval to be statistically significant in determining the risk of death of post- neonates in urban Kenya. Current work status of the mother and number of antenatal care visits done by the mother were found not to be significantly related to early childhood mortalities both in urban and rural Kenya.

In rural Kenya, mothers with primary educational qualifications had a lower risk of reporting neonate and infant deaths compared to those with no any educational qualifications. This is contrary to the findings of a recent study by Omedi and Wanjiru (20/4) on "Determinants of infant mortality in rural Kenya" which found no significant association between maternal education and infant death. The 
statistical significance in this study indicates the contribution of maternal education to the observed infant mortality decline in rural Kenya. Any increase in maternal education is associated with a number of benefits on child health since educated people are more likely to use maternity care and child health care services. The study found births to women with some secondary education to be at a 0.772 lesser risk of dying at post-neonate stage in urban areas of Kenya.

Generally, post-neonates and infants born in high wealth index households were at a greater risk of death than their counterparts in low wealth index households both in urban and rural Kenya. Probably, children in such households are weaned and introduced to other meals at tender ages against the recommended exclusive breastfeeding in the first six months of life. It is in such households that mothers are busy amassing wealth at the expense of creating some extra time for their babies. A study done by Faye et al. (2016) found the risk of child mortality to be significantly higher among households of average socio-economic status than among the poorest households in Korogocho, Kenya. At neonatal stage however, the study found neonates in high wealth index households to be at a 0.429 (Model l-urban) and 0.415 (Model III-rural) lesser risk of dying than those in low wealth index households. Neonatal deaths are basically biological and this may point to the good care accorded to the expectant mothers in such households.

In urban Kenya, the study found female births and births occurring at a preceding birth interval of at least 24 months to be at a 0.692 and 0.726 lesser risk, respectively, of dying as post-neonates compared to male births and those births occurring at a less than 24 months preceding birth interval. For the sex of birth, this is an expected observation since, generally, there occurs more male than female births, but as time goes by, males tend to die more than females since the female sex is biologically stronger than the male sex. A higher preceding birth interval has been attributed to a lesser risk of childhood mortalities (DoS and ICF Macro, 2010; Mondal et al., 2009). Delayed conception enables the mother to regain her strength and prepares her to accord sufficient care to the newborn given that the previous birth has adapted to the external environment. Encouraging more women to delay childbearing and providing sufficient services for the same will see an emaciated infant mortality in Kenya.

Unexpectedly, the study found higher probabilities of infant mortality among older mothers in urban areas of Kenya. In Model II, the risk of infant mortality is 135.5 percent and 348.2 percent higher among mothers aged 30 to 39 and 40 to 49 , respectively, at a statistical significance of 95 percent. As explained by La Grew et al. (1996) and Brown and Eisenberg (1995), older women suffer increased risks of poor birth outcomes due to biological risks of increased likelihoods of such medical conditions as diabetes and hypertension, and higher rates of unintended pregnancies compared to younger women. Such medical conditions are highly reported in urban than rural areas. In his study on "Neighbourhood characteristics and under-five mortality in Nigeria", Adedini (20/4) found a significant higher risk of mortality among births to older mothers above 35 years than to younger mothers aged 15-24 years. In rural Kenya however, the study found infant mortality risk to be lower among women aged above 20 years than among those aged less than 20 years. As mentioned by Taffa and Obare (2004), children of young mothers might be prone to have severe forms of infections and likely to die of it, and that this is a double disadvantage for teenagers living in poor rural areas. A study by Omedi (20/4) found 70.56 percent of adolescent mothers to be of rural residence and that girls residing in an urban environment were 43 percent less likely to be mothers compared to girls residing in a rural environment at a $\rho$-value of 0.01 in a logistic regression model.

The risk of infant death decreased with an increase in the size at birth of the newborn in rural areas. Small size babies are likely to be preterm and births delivered under caesarian section due to maternal complications who, once exposed to the external conditions in rural areas, remain weakened and at elevated risks of dying. In urban Kenya, the study found the risk of a post-neonate dying to be 7.413 and 4.055 among average and large sized births than among small sized births while that of a neonate death was 0.654 lesser among average sized births than among small sized births.

Deliveries in a health facility were found to be at lesser risks of yielding to post-neonate deaths in urban areas compared to home deliveries. Known is the fact that hospital deliveries are more likely to occur under skilled delivery care and in salubrious conditions than those deliveries occurring elsewhere. However, the study found the risk of a neonate dying in rural areas to be 61.6 percent higher among those delivered in public health facilities compared to those delivered at home. The same trend was observed in the infant category. This might be explained by the fact that not all health facilities in rural areas are of the expected standards in terms of resources and services offered. Mothers in such hospitals might struggle to give birth with no or minimal assistance because of the doctor-patient ratio compared to a home delivery which is likely to occur under the supervision of an experienced midwife. 


\section{Conclusion and recommendations}

This study aimed at ascertaining factors responsible for the observed reversal in infant mortality in urban and rural Kenya which are in favor of rural areas. In the period 1993 - 2003, infant mortality rate was 61 (urban) and 79 (rural) and in the period $2005-2014$, the rate was 43 (urban) and 40 (rural), a 29.5 percent urban decline and 49.4 percent rural decline. 2014 Kenya demographic and survey data was fitted on the Cox proportional hazards model to bring out the risk of a neonate, post-neonate or infant dying based on the selected independent variables. Analytical results indicated that higher educational qualifications of the mother, female births, preceding birth interval of at least 24 months and health facility deliveries favor reductions in early childhood mortalities in urban areas of Kenya whereas higher wealth index, higher maternal ages and large sizes at birth disfavor reductions in early childhood mortalities. In rural Kenya, the study found some maternal education, increased age at motherhood and large sizes at birth to favor early childhood mortality reductions whereas increased household wealth indices and deliveries in health facilities disfavor such reductions. Current work status of the mother and number of antenatal care visits done by an expectant mother were found not significant in explaining the risk of death in early childhood stages.

For the urbanites, the lifestyle needs to be regulated in favor of good maternal and child health to check on the observed higher risks of death due to high household wealth index, high maternal ages and average and large sizes at birth. Worth noting is that an increase in the age of the mother is likely to translate to an increase in the household wealth yet both have been found to disfavor reductions in mortalities. Among the rural dwellers, there is need to equip health facilities with the necessary resources, equipment and manpower to ensure safe, supervised deliveries in hygienic conditions that shall fascinate more people to do hospital at the expense of home deliveries. Again, regulating the lifestyles in high wealth index households will be key in the effort to reduce infant mortality further. Encouraging more women to postpone age at motherhood and to go to school before entry into childbearing will even make the mortality reduction mission more successful. There is need to investigate the effect of work status of the mother and uptake of antenatal care visits on infant mortality, this study having failed to find any statistical relationship between them.

\section{References}

Abou-Ali H. (undated). Child Mortality, Wealth and Education: Direct versus Indirect Effects.
Environmental Economics Unit, Department of Economics, Goteborg University, Sweden.

Adedini S. A. 2014. Neighborhood Characteristics and Under-five Mortality in Nigeria. African Population Studies, Vol. 27, No. 2 Supplement.

Ajaari J., Masanja H., Weiner R., Abokyi S. A. and Owusu-Agyei S. 2012. Impact of Place of Delivery on Neonatal Mortality in Rural Tanzania. International Journal of $\mathrm{MCH}$ and AIDS, Volume I, Issue I.

Babalola S. and Fatusi A. 2009. Determinants of Use of Maternal Health Services in Nigeria- Looking Beyond Individual and Household Factors. BMC Pregnancy and Childbirth, 2009; 9:43.

Brockerhoff M. and Brennan E. 1998. The Poverty of Cities in Developing Countries. Population and Development Review 24:75-I I4.

D.C. La Grew, Jr., et al. 1996. Advanced Maternal Age: Perinatal Outcome when Controlling for Physician Selection. Journal of Perinatology, 16: 256-260.

Doctor H. V. 20I I. Does Living in a Female-Headed Household Lower Child Mortality? The Case of Rural Nigeria. Rural and Remote Health; I I.

Ettarh R. R. and Kimani J. 20I2. Determinants of Under-five Mortality in Rural and Urban Kenya. Rural and Remote Health 12: 1812.

Faye C. M., Mutisya M., Elungata P. and Beguy D. 2016. Correlates of Spatial Differences in Underfive Mortality in Nairobi's Informal Settlements. African Population Studies, Vol. 30, No. 3, 2016.

Fotso J. C. 2007. Urban-Rural Differentials in Child Malnutrition: Trends and Socio-Economic Correlates in sub Saharan Africa. Health and Place 13:205-223.

Gabrysch S. and Campell O. M. R. 2009. Still too far to walk: Literature review of the Determinants of Delivery Service Use. BMC Pregnancy and Childbirth 2009; 9:34.

Kenya National Bureau of Statistics \& ICF Macro. 2015. Kenya Demographic and Health Survey 2014. Calverton, Maryland: KNBS and ICF Macro.

Kenya National Bureau of Statistics and ICF Macro. 2010. Kenya Demographic and Health Survey 2008/09. Calverton, Maryland: KNBS and ICF Macro.

Lalou R. and LeGrand T. 1997. Child Mortality in the Urban and Rural Sahel. Population: An English Selection 9: 147-68.

Mondal N. I., Hossain K. and Ali K. 2009. Factors Influencing Infant and child Mortality: A Case Study of Rajshahi district, Bangladesh. J Hum Ecol, 26(I).

Mosley W. H. and Chen L. 1984. An Analytical Framework for the Study of Child Survival in 
Developing Countries. Population and Development Review, Supplement to Volume 10.

Omedi, G. 20I4. Adolescent Motherhood in Kenya. Research on Humanities and Social Sciences, Volume 4, Number 23.

Omedi, G. and Wanjiru, G. Determinants of Infant Mortality in Rural Kenya. Research on Humanities and Social Sciences, Volume 4, Number 28.

Pandey A., Choe M. K., Luther N. Y., Sahu D. and Chand J. 1998. Infant and Child Mortality in India. National Family Health Survey Subject Reports: Number II. Indian Institute of Population Sciences, Mumbai.

Reichman, N.E. and Pagnini, D.L. 1997. Maternal Age and Birth Outcomes: Data from New Jersey. Perspectives on Sexual and Reproductive Health. A journal of peer-reviewed research.

Say L. and Raine, R. 2007. A Systematic Review of Inequalities in the Use of Maternal Health Care in Developing Countries: Examining the Scale of the problem and the Importance of Context. Bulletin of the World Health Organisation 85:8I 2- I9.

S.S. Brown and L. Eisenberg (eds) 1995. The Best Intentions: Unintended Pregnancy and the WellBeing of Children and Families, National Academic Press, Washington DC.

Taffa N. and Obare F. 2004. Pregnancy and Child Health Outcomes among Adolescents in Ethiopia. Ethiopian Journal of Health Development; I8(2).

Worku Z. 2009. Factors that Affect Under-five Mortality among South African Children: Analysis of the South African Demographic and Health Survey Dataset. Proceedings of the World Congress on Engineering and Computer Science.

Van de Poel E., O'Donnell, O. and van Doorslaer E. 2009. What Explains Rural-Urban Gap in Infant Mortality: Household or Community Characteristics? Demography, Volume 46Number 